\title{
CORRECTION
}

D) Check for updates

Cite this: J. Mater. Chem. A, 2018, 6, 4879

\author{
DOI: $10.1039 / \mathrm{c} 8 \mathrm{ta9} 9045 \mathrm{k}$ \\ www.rsc.org/MaterialsA
}

\section{Correction: Nitrogen-doped carbons prepared from eutectic mixtures as metal-free oxygen reduction catalysts}

\author{
Nieves López-Salas, ${ }^{a}$ María C. Gutiérrez, ${ }^{a}$ Conchi O. Ania, ${ }^{b}$ \\ Miguel A. Muñoz-Márquez, ${ }^{c}$ M. Luisa Ferrer ${ }^{a}$ and Francisco del Monte*a \\ Correction for 'Nitrogen-doped carbons prepared from eutectic mixtures as metal-free oxygen reduction \\ catalysts' by Nieves López-Salas et al., J. Mater. Chem. A, 2016, 4, 478-488.
}

The authors regret the omission of an Acknowledgements section in the original manuscript. The Acknowledgements section should be as below.

\section{Acknowledgements}

This study was supported by MINECO (Project Numbers MAT2012-34811 and MAT2015-68639-R). N. L.-S. acknowledges MINECO for a FPI contract.

The Royal Society of Chemistry apologises for these errors and any consequent inconvenience to authors and readers.

\footnotetext{
anstituto de Ciencia de Materiales de Madrid-ICMM, Consejo Superior de Investigaciones Científicas-CSIC, Campus de Cantoblanco, 28049 Madrid, Spain. E-mail: delmonte@ icmm.csic.es; Tel: +34913349033

${ }^{b}$ Instituto Nacional del Carbon-INCAR, Consejo Superior de Investigaciones Científicas-CSIC, C/Francisco Pintado Fe, 26, 33011 Oviedo, Spain ${ }^{c}$ CIC Energigune, Parque Tecnológico de Álava, Albert Einstein, 48, 01510 Miñano, Spain
} 